\title{
Study protocol of comprehensive risk evaluation for anorexia nervosa in twins (CREAT): a study of discordant monozygotic twins with anorexia nervosa
}

Maria Seidel ${ }^{1,2+}$, Stefan Ehrlich ${ }^{1 * \dagger}$, Lauren Breithaupt ${ }^{3,4}$, Elisabeth Welch ${ }^{5,6}$, Camilla Wiklund ${ }^{2}$, Christopher Hübel ${ }^{2,7,8,9}$, Laura M. Thornton ${ }^{10}$, Androula Savva², Bengt T. Fundin², Jessica Pege ${ }^{2}$, Annelie Billger ${ }^{2}$, Afrouz Abbaspour ${ }^{2}$, Martin Schaefer ${ }^{10}$, Ilka Boehm ${ }^{1}$, Johan Zvrskovec ${ }^{2,7}$, Emilie Vangsgaard Rosager ${ }^{11}$, Katharina Collin Hasselbalch ${ }^{11}$, Virpi Leppä2 ${ }^{2}$ Magnus Sjögren ${ }^{11,12}$, Ricard Nergårdh ${ }^{13}$, Jamie D. Feusner ${ }^{14}$, Ata Ghaderi, ${ }^{7},{ }^{10}$ and Cynthia M. Bulik $2,15,16^{*}$

\begin{abstract}
Background: Anorexia nervosa (AN) is a severe disorder, for which genetic evidence suggests psychiatric as well as metabolic origins. AN has high somatic and psychiatric comorbidities, broad impact on quality of life, and elevated mortality. Risk factor studies of AN have focused on differences between acutely ill and recovered individuals. Such comparisons often yield ambiguous conclusions, as alterations could reflect different effects depending on the comparison. Whereas differences found in acutely ill patients could reflect state effects that are due to acute starvation or acute disease-specific factors, they could also reflect underlying traits. Observations in recovered individuals could reflect either an underlying trait or a "scar" due to lasting effects of sustained undernutrition and illness. The co-twin control design (i.e., monozygotic [MZ] twins who are discordant for AN and MZ concordant control twin pairs) affords at least partial disambiguation of these effects.
\end{abstract}

Methods: Comprehensive Risk Evaluation for Anorexia nervosa in Twins (CREAT) will be the largest and most comprehensive investigation of twins who are discordant for AN to date. CREAT utilizes a co-twin control design that includes endocrinological, neurocognitive, neuroimaging, genomic, and multi-omic approaches coupled with an experimental component that explores the impact of an overnight fast on most measured parameters.

(Continued on next page)

\footnotetext{
* Correspondence: stefan.ehrlich@uniklinikum-dresden.de; cynthia.bulik@ki.se

${ }^{\dagger}$ Maria Seidel and Stefan Ehrlich are joint first authors.

${ }^{1}$ Division of Psychological and Social Medicine and Developmental

Neurosciences, Faculty of Medicine, Technische Universität Dresden,

Fetscherstraße 74, 01307 Dresden, Germany

${ }^{2}$ Department of Medical Epidemiology and Biostatistics, Karolinska

Institutetet, Nobels väg 12A, 17165 Stockholm, Solna, Sweden

Full list of author information is available at the end of the article
}

(c) The Author(s). 2020 Open Access This article is licensed under a Creative Commons Attribution 4.0 International License, which permits use, sharing, adaptation, distribution and reproduction in any medium or format, as long as you give appropriate credit to the original author(s) and the source, provide a link to the Creative Commons licence, and indicate if changes were made. The images or other third party material in this article are included in the article's Creative Commons licence, unless indicated otherwise in a credit line to the material. If material is not included in the article's Creative Commons licence and your intended use is not permitted by statutory regulation or exceeds the permitted use, you will need to obtain permission directly from the copyright holder. To view a copy of this licence, visit http://creativecommons.org/licenses/by/4.0/ The Creative Commons Public Domain Dedication waiver (http://creativecommons.org/publicdomain/zero/1.0/) applies to the data made available in this article, unless otherwise stated in a credit line to the data. 
(Continued from previous page)

Discussion: The multimodal longitudinal twin assessment of the CREAT study will help to disambiguate state, trait, and "scar" effects, and thereby enable a deeper understanding of the contribution of genetics, epigenetics, cognitive functions, brain structure and function, metabolism, endocrinology, microbiology, and immunology to the etiology and maintenance of AN.

Keywords: Twin study, Risk factors, Study protocol, Cognitive functions, Neuroimaging, Genetics, Metabolism, Microbiota, Anorexia nervosa

\section{Background}

We present the study protocol for the Comprehensive Risk Evaluation for Anorexia nervosa in Twins (CREA $\mathrm{T})$ : A study of monozygotic (MZ) twins who are discordant for anorexia nervosa (AN). AN is a complex and serious disorder characterized by prolonged undernutrition, low weight, weight/shape concerns [3] and is often accompanied by pathologically elevated physical activity. Individuals with AN present with considerable somatic and psychiatric comorbidity [130]. Mortality associated with AN is significantly elevated [2] and higher than in other serious psychiatric disorders, such as schizophrenia, bipolar disorder, and major depression [21]. Rates of relapse and hospital readmission are high $[34,116,130]$. Consequently, the disorder places a major social and financial burden on patients, family members, and the health care system [112]. No medications are effective in the treatment of the core symptoms of AN [130] and drug development has been hindered by a lack of understanding of the (neuro) biology of the disorder and a systematic integration of those biological factors with environmental components [88]. Until we gain a deeper understanding of the biology of the illness, we will be unable to determine which factors place individuals, or more nuanced questions such as which factors enable individuals with $\mathrm{AN}$ who do not die from the disorder to maintain dangerously low body mass indices (BMI), often for prolonged periods of time, without succumbing to medical complications of severe starvation or other opportunistic illnesses [16].

\section{Study overview}

To address these aforementioned knowledge gaps and to inform treatment development, we employ a co-twin control design - an investigation of discordant MZ twins (i.e., twin pairs in which one twin has a target disorder and the other remains unaffected, despite being past the age at risk of onset for the illness). We are recruiting 50 pairs of female MZ twins in which one has or has had $\mathrm{AN}$, and $\sim 50$ pairs of age matched female control $\mathrm{MZ}$ twins in which neither twin has any history of eating disorders symptoms.

The study is made possible by the existence of the Swedish [69, 75] and Danish [107, 108] twin registers and the rich national health registers in both countries $[29,72,73,84]$. This will allow us to identify all twins in each country in which one twin has an identified diagnosis of AN.

As discordant $\mathrm{MZ}$ twins are both rare and highly valuable to health research, we have assembled an experienced interdisciplinary team to design a comprehensive investigation that will thoroughly explicate the role of genetic, epigenetic, neurocognitive, neural, endocrinological, metabolic, microbial, immunological, and environmental factors associated with AN. We employ a longitudinal, multimodal co-twin control design that includes an experimental component, namely an 18-h overnight fast. This experimental component affords us the opportunity to observe differential response to fasting across a range of biological and psychological outcome domains.

\section{The value of co-twin control designs}

The study of discordant MZ twins represents a powerful research strategy to explore factors that influence differences between individuals who are fundamentally genetically identical. Discordant $\mathrm{MZ}$ twins are a natural experiment in which appropriate matching occurs. The validity of twin research also rests on the assumption that environmental factors are also shared equally between MZ twins (during early life). As one can therefore assume background genetic matching, observed differences in the relevant traits can be due to differential exposures, consequences of the illness, epigenetic processes, or the state of recovery of the affected twin. Due to the prevalence of AN, co-twin control studies in this field have been rare and small [54, 93, 114, 119]. Below we describe each component of CREAT including a concise background, relevance, and expected outcomes.

\section{Study aims and protocol overview}

Previous studies on risk factors for AN have often focused on differences between acutely ill and recovered individuals. However, this design lends itself to some ambiguity in interpretation. Differences observed in acutely ill patients could reflect state effects due to acute starvation or acute disease-specific factors, or could 
represent underlying traits. Alternatively, observations in recovered individuals could reflect either an underlying trait or a "scar", due to lasting effects of sustained undernutrition and illness [89]. We anticipate that approximately half of the participating twins with AN will be recovered. Recovery criteria in the current study follow a modified version of Bardone-Cone et al. [6] and include 1) physical recovery: $\mathrm{BMI} \geq 18.5 \mathrm{~kg} / \mathrm{m} 2$; 2) behavioral recovery: no binge eating, purging, or fasting in the past year, and 3) psychological recovery: all Eating Disorder Examination-Questionnaire (EDE-Q; [30]) subscales within 1 SD of age-matched community norms. Further, we anticipate that about $25 \%$ will be actively ill (i.e., meet threshold diagnostic criteria), and $25 \%$ will be partially recovered, falling between ill and recovered on either physical, behavioral, or psychological parameters. Using a discordant MZ twin design as well as different recovery states the current study will help to disentangle not only state and trait effects, but also "scar" effects (comparisons as outlined in Fig. 1) across several different investigational domains. Briefly, in a two-day study, all participating twins undergo blood sampling, neuroimaging, neurocognitive testing, body composition measurement via dual X-ray absorptiometry (DXA), accelerometer-based activity monitoring, microdialysis, self-report questionnaires, and structured interviews over a $28-30 \mathrm{~h}$ period with standardized food intake and a monitored overnight fast (Fig. 2).

\section{Experimental overnight fast}

Appetite regulation and, therefore, the motivation to eat reflects a complex integration of several physiological signals influencing hunger, satiety, physical activity, and cognitive processes that affect the subjective value of food $[60,120]$. The relentless and pervasive caloric restriction during periods of extreme low body weight and hallmark endocrine disturbances that accompany eating behavior [101] suggest disrupted homeostatic influences on reward processing $[33,85]$. The majority of studies in acute AN to date are unable to disaggregate the effects of fasting from confounding effects of long-term mal- or undernutrition. However, altered responses to shortterm fasting persist even after weight restoration [44, 124], suggesting persistent traits underlying the AN phenotype and associated pathological eating behavior. Our experimental overnight fast allows us to document differences between affected twins and their unaffected co-twins, as well as between discordant affected MZ case twins and concordant unaffected MZ control twins in neuronal, neurocognitive, metabolic, endocrinological, and psychological response to short-term food restriction by repeating assessments across a number of domains pre- and post-fast while holding other variables constant.

\section{Genomics \& Epigenetics}

AN is highly familial. Twin studies estimate between 28 and $74 \%$ of the variance in liability is attributable to genetic factors [127]. The most recent genome-wide association study (GWAS) identified eight genomic loci associated with AN, with genetic correlations suggesting both metabolic and psychiatric risk factors for the illness. These recent findings advance previous notions of a re-conceptualization of the illness as a metabopsychiatric condition $[42,58,121]$. In addition to genetic risk, the AN phenotype and disease course could also be shaped by epigenetic mechanisms. Epigenetics refers broadly to the regulation of gene expression without a change in the DNA coding sequence. Unlike the genome sequence, epigenetic marks can be subject to environmental stimuli starting immediately after conception [79], which play a role in AN, including hormones, nutrition, lifestyle, and intestinal microbiota [2, 79, 91]. Epigenetic studies to date have focused solely on the role of DNA methylation [45, 46]. We expect that affected twins will differ in their epigenetic signature, including DNA modifications, histone modifications, and noncoding RNAs, and that differences between discordant twins, especially the recovery status of the affected twin, may aid identifying illness-related (state) effects (Fig. 1 A) versus "scar" effects from chronic undernutrition (see Fig. 1 C).

\section{Neuropsychology}

Several neurocognitive functions such as set-shifting, value-based decision making, and central coherence have been reported to be altered in AN $[1,115,123]$. The extent to which these alterations are trait or state markers remains unclear. Observations in individuals with acute $\mathrm{AN}$, recovered $\mathrm{AN}$, and unaffected sisters or mothers suggest that deficiencies in set shifting may be a trait marker in AN [61, 63, 71, 97, 123]. On the other hand studies in adolescent patients have not replicated impairments in set-shifting, suggesting that chronic illness might have contributed to positive findings [62].

Consistent with the clinical presentation of elevated self-control in AN [53], delay discounting (i.e., the depreciation of the value of a reward related to the time of retrieval), and probability discounting have been reported to be altered in AN patients $[8,26,110,111]$. Some studies suggest that AN patients have a preference for larger delayed rewards when compared to healthy individuals whereas studies in younger AN patients did not find differences in discounting behavior [56, 96]. Multiple studies have also observed weak central coherence - reduced global and integrated processing and enhanced focus on detail [35] - in underweight individuals with $\mathrm{AN}$, and in some studies in unaffected relatives [37, $61,63,98]$, yet there are conflicting reports about 

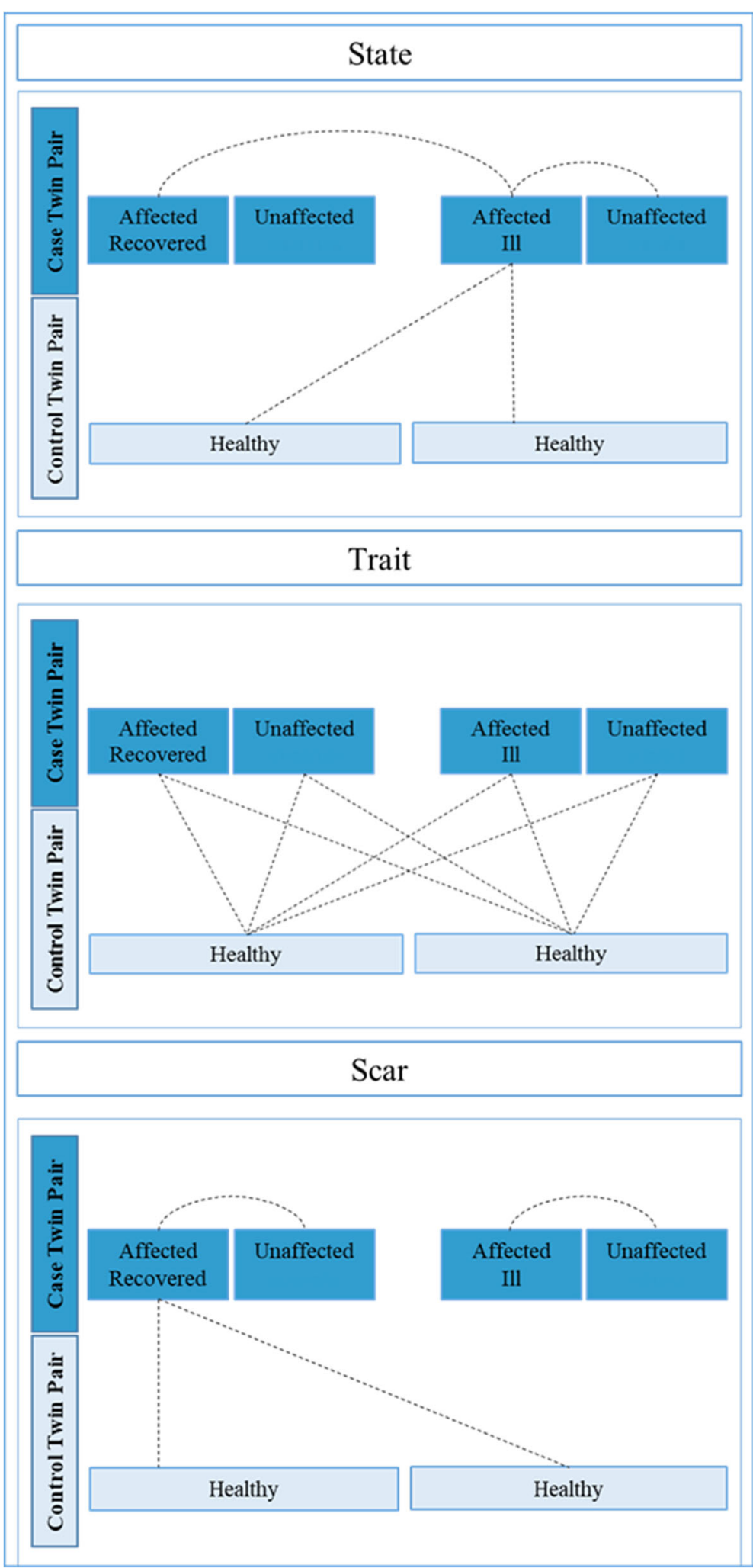

Fig. 1 Overview of possible comparisons between twins to investigate whether effects constitute state, trait, or "scar" markers. Lines indicate comparisons where observed differences would imply state, trait, or "scar" effects respectively 


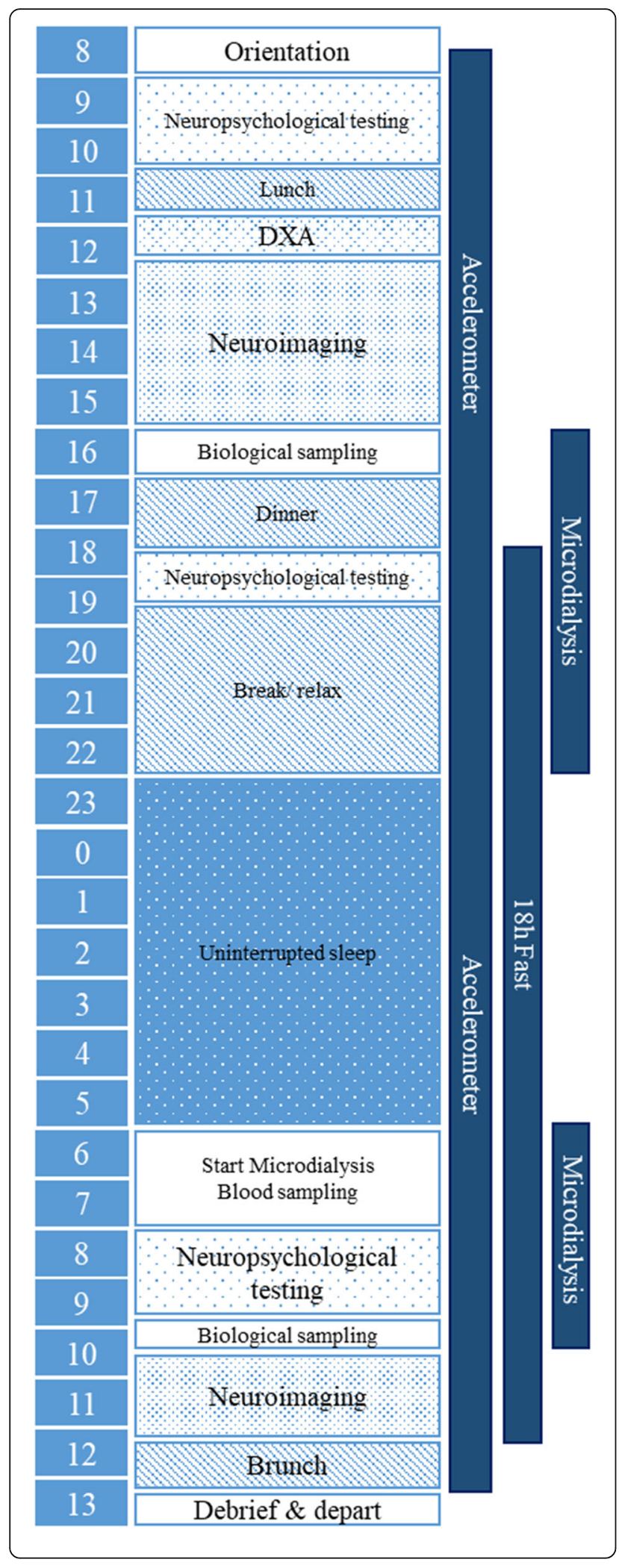

Fig. 2 Overview of the study schedule. Participants undergo a $30 \mathrm{~h}$ protocol, starting at 8:30 am in the morning of day 1 until approximately 1:00 pm of day 2 . Study components flow as per Fig. 3. Individuals wear an accelerometer for $29 \mathrm{~h}$ of the study. The fasting period commences at 18:30 following dinner on day 1 and continues until 12:30 on day 2 . Neurocognitive testing,

neuroimaging, biological sampling, and microdialysis are conducted before (T1) and after (T2) the experimental fast

whether this persists in weight-restored or recovered states $[61,63,122]$. Preliminary evidence in healthy individuals suggests that short term fasting affects both setshifting and central coherence [7, 13, 87]. The experimental overnight fast allows us to observe whether short term food deprivation differentially modifies cognitive functioning in affected versus unaffected twins, and in comparison to concordant unaffected MZ control twins.

\section{Neuroimaging}

Structural brain changes, i.e., the reduction of gray matter (GM) and white matter (WM), are most pronounced in acutely underweight patients with $\mathrm{AN}[55,57,104]$ with normalization occurring quite rapidly after shortterm recovery $[9,10,118]$. Standard designs have been unable to differentiate state (due to undernutrition, even after recovery) and trait effects. The co-twin control design has the potential to aid in disaggregating these effects and potentially identifying trait effects in structural changes in AN.

Accumulating evidence of functional MRI (fMRI) data further points to alterations within established resting state networks $[11,12,24,77,100]$ as well as during specific tasks. Domains reported to be altered in AN include reward processing [85], food-cue reactivity [129], emotion recognition and processing $[95,103,129]$, and general visual processing $[66,67]$. The relative contribution of trait, state, or "scar" factors of these alterations will be visible in the difference between a) the affected and currently ill and the unaffected discordant twin (state), b) the unaffected discordant twin and twin controls (trait), and c) the affected now recovered and unaffected discordant twin ("scar") respectively (see Fig. 1). Reward processing and food cue reactivity are expected to be modulated by the nutritional status of the patients, i.e., whether patients are acutely ill or weight-restored and whether patients are scanned after a period of fasting or after a meal $[64,124]$.

\section{Endocrinology \& Metabolism}

AN has far reaching effects on most endocrine systems $[47,101]$. This is unsurprising as the endocrine system plays a major role in adaptation to an ever-changing environment with varying demands on how to eat, use, and store energy. Being able to adapt to periods of food 
restriction, negative energy balance, and even starvation is essential for most animals and, not surprisingly, starvation has broad impact on metabolism, reproduction, and behavior. In the CREAT study we will compare endocrine and metabolic responses to food restriction between discordant $\mathrm{MZ}$ twins. Early metabolic changes in response to the overnight fast will be captured by microdialysis. The microdialysis technique, described in detail elsewhere [52], places a probe in subcutaneous fat, allowing observation of how glucose homeostasis is maintained via different metabolic pathways, e.g., activation of lipolysis and gluconeogenesis. We will also measure key metabolic hormones such as cortisol, ghrelin, and thyroid hormones. Our experimental design will enable us to differentiate between early differences in response to fasting from secondary effects of starvation as well as separate biomarkers of negative energy balance from biomarkers of the disorder. We hypothesize that an identifiable metabolic/endocrine response to negative energy balance is associated with an increased risk of developing $\mathrm{AN}$.

\section{Intestinal microbiome}

The human intestinal microbiota is a complex and dynamic community of microorganisms that plays a fundamental role in many host processes including energy metabolism [18] and immunity [36], as well as broad regulation of mood [27] and behavior [83]. Dysbiosis of the intestinal microbiota has been associated with a diverse range of health deficits [48]. Several studies have confirmed differences in the diversity and composition of the intestinal microbiota in individuals with AN and controls, and across the course of therapeutic renourishment $[4,14,59,74,81,82,102]$. It is possible that alterations in the intestinal microbiota are adaptive responses to an extreme intestinal environment during acute stages of $\mathrm{AN}$, allowing survival during periods of starvation. Another possibility is that the gut microbiota plays a cocausal role in AN, although the mechanism for this requires further explication. Although the aforementioned studies provide valuable findings that give us an outlook for future investigations, their study designs do not allow elaborating beyond associations nor do they disambiguate state, trait, or "scar" effects. We will compare fecal microbiota (as a proxy to study intestinal microbiota) in affected versus discordant unaffected co-twins (to identify state-related alterations), unaffected discordant twins and twin controls (to pinpoint trait-related changes), and affected recovered twins versus unaffected discordant co-twins (to assess "scar"-related alterations). Relating the microbiota data to dietary and metabolic data will help explicate the role of microbial variability in the availability and absorption of nutrients from the gut and, potentially, in modulating host factors. As epigenetic regulation is a potential mechanism through which gut microbiota and microbial metabolites can affect host factors, we will also investigate the associations between epigenetic data and microbiota data in our study groups.

\section{Immunology}

The blood-brain barrier and the blood-cerebrospinal fluid barrier separate the neuroimmune system from the peripheral immune system. However, the communication between them is possible via cytokines that can influence a variety of brain functions relevant to behaviour including neurotransmitter metabolism, neuroendocrine function, synaptic plasticity, and neurocircuits that regulate mood, anxiety, and motivation [19]. Higher concentrations of the cytokines tumor necrosis factor $\alpha$ (TNF $\alpha)$ and interleukin 6 (IL-6) have been reported in AN compared with healthy controls but may not be specific for AN [25]. Longitudinal investigations of cytokines have not yet been conducted, therefore, it is difficult to judge whether these alterations are trait-related or a sequelae of AN [25], but initial evidence suggests that individuals with AN seem to carry genetic variants predisposing them to lower C-reactive protein (CRP) concentrations [70]. Additionally, a bidirectional relationship between AN and autoimmune diseases, such as ulcerative colitis and Crohn's disease, and an increased risk for AN after a preceding diagnosis of type 1 diabetes has been reported and replicated [43, 92, 126, 128]. The cooccurrence is not yet fully understood, but no shared genetic liability between autoimmune diseases and AN has been detected so far [117]. The existing findings encourage the exploration of other factors, such as infections, medication [15], insulin, diet or starvation effects as potential candidates to explain the relationship between AN and abnormalities of the immune system and/ or autoimmune diseases. We also aim to understand whether the effects of either ongoing subtle cell damage or an unusual pattern of inflammation are exacerbated by a lack of adipose tissue which alters the expected production of mediators and the interrelationship of cytokines.

\section{Methods}

Basic characteristics and diagnosis Participants

We are recruiting female MZ twins rigorously discordant for AN and healthy non-dieting age- matched female concordant unaffected MZ twin controls. The twins are identified and recruited from the Swedish Twin Registry (STR) [69] and the Danish Twin Registry (DTR) [107, 108]. The STR was first established in the late 1950s and includes about 200,000 twins, providing an invaluable and unique resource for scientific studies such as CREA T. The Danish Twin Register (DTR) was initiated in 
1954 and covers all twin cohorts established in Denmark since 1870. The DTR contains more than 85,000 twin pairs and a similarly valuable resource for health research.

We intend to enroll $50 \mathrm{MZ}$ discordant twin pairs and $50 \mathrm{MZ}$ concordant unaffected control pairs $\left(\mathrm{N}_{\text {total }}=\right.$ 200). Participants are reimbursed for participation with a fixed amount of 4000 Swedish kronor, which they receive after completion of the study.

\section{Inclusion-exclusion criteria}

Stage 1 Initial screen: The Stage 1 review determines preliminary eligibility (females only, aged between 18 and 50 Fig. 3). Twins who appear to be MZ and discordant for AN based on diagnostic information obtained via participation in the STR [68] are sent an invitation to participate in Stage 1. Danish twins are identified by selecting a cohort of all MZ female twins, age 18-50 from the DTR ( $n=1617$ pairs, where both twins are alive per 1st of October 2018) or via social media or contacts with healthcare providers. Via the Danish National Patient Register [73] and Psychiatric Central Research Register [84], this cohort will be matched for the diagnosis of AN and contact information obtained via the Civil Registration System. After giving informed consent, each twin pair is genotyped to verify monozygosity (for details see Supplementary Material 1.1, Additional file 1). In addition to the saliva kits for the monozygosity screening, participants are also provided with a link to a validated diagnostic online questionnaire, ED100K [113] which captures lifetime DSM-5 eating disorder diagnoses. This is a second stage of verifying that affected twins did indeed have AN and that co-twins and control twins are unaffected.

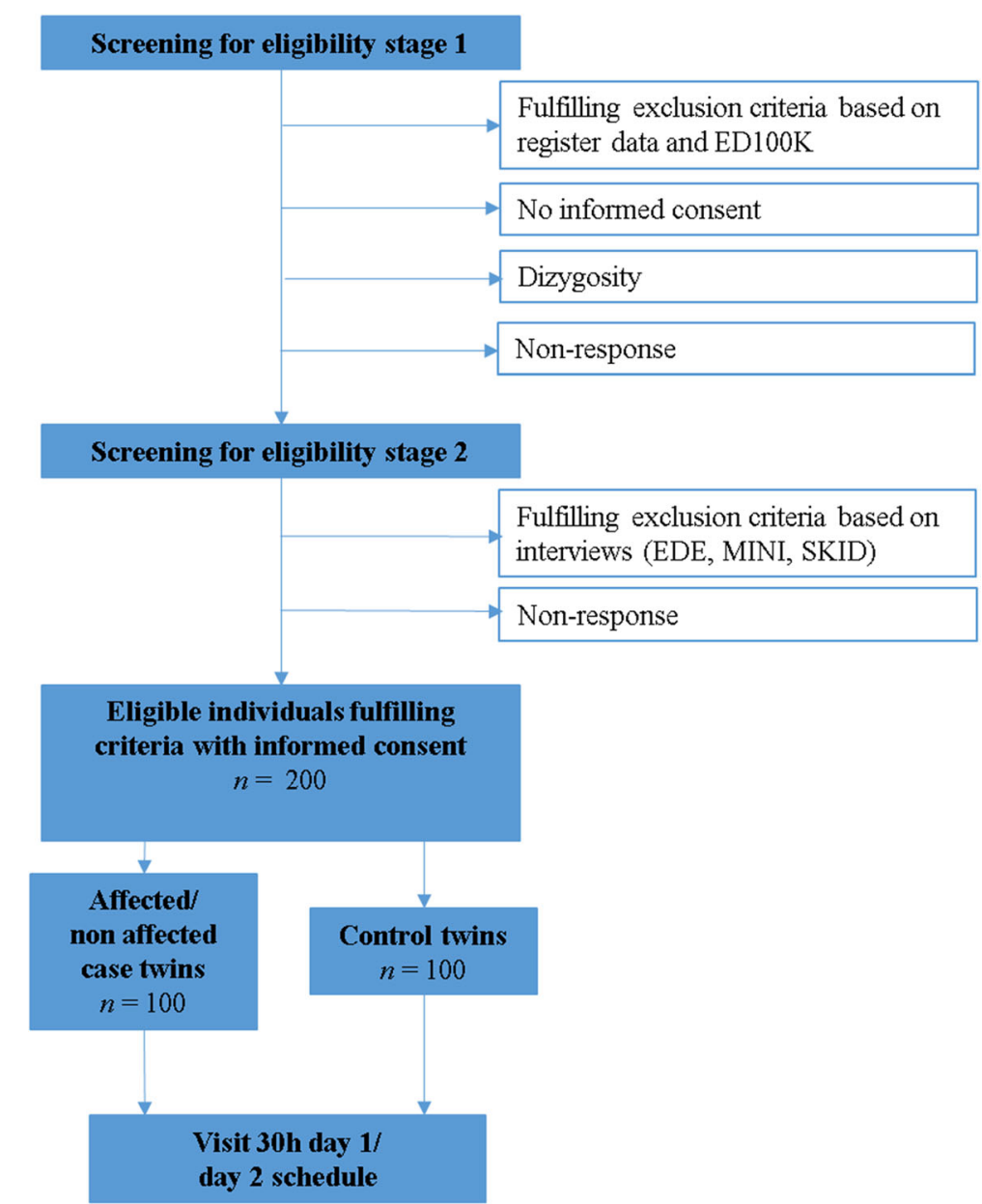

Fig. 3 Inclusion $(\downarrow)$ /Exclusion $(\rightarrow)$ procedures for recruitment. Pre-screening begins at Stage 1. Individuals are screened with the ED100K online questionnaire [113] for lifetime eating disorder symptoms as well as genetic testing. Participants are excluded if screening reveals them to be dizygotic or if the unaffected co-twin is discovered to be affected. Screening at Stage 2 is more intensive and includes telephone interviews by trained interviewers conducting the Eating Disorder Examination [EDE [23]], Mini-International-Neuropsychiatric-Interview [MINI, [106]], and the Eating Disorders section of the Structured Clinical Interview for DSM-5 [SCID-5 [32]]. If all criteria fulfilled and participants remain interested in participating, they are invited to participate in the $30 \mathrm{~h}$ study protocol 
Stage 2 Pre-visit evaluations: MZ twins who are confirmed to be MZ via genotyping and who appear to meet eligibility criteria after Stage 1 undergo a phone-based interview including the complete Eating Disorder Examination (EDE [23]) for assessing current diagnosis of eating disorder, and eating disorder-specific psychopathology. For control twins, a short version of the EDE (only diagnostic questions) is used. The EDE is a reliable, valid, and widely used instrument for diagnosing eating disorders, and has been translated into Swedish and Danish. In both twin groups, the Eating Disorders module of the SCID-5 [32] is used to assess the lifetime illness course and recovery status. The assessments are performed by clinically trained research staff who are experienced in psychiatric diagnostic assessments in general and eating disorders in particular.

Our definition of rigorous discordance is that the affected twin should meet or have met modified DSM-5 criteria for AN at some point in their life, and the unaffected twin should not meet any current or past criteria for $\mathrm{AN}$ or any other eating disorder. In addition, the unaffected twin should have been unaffected for at least five years after the onset of their co-twin's AN, have a lifetime minimum adult BMI above the underweight cut off $\left(18.5 \mathrm{~kg} / \mathrm{m}^{2}\right)$, and not suffer from other metabolic conditions that could influence body weight or appetite.
After evaluating all inclusion and exclusion criteria, all twin pairs undergo a second phone-based interview using the MINI International Neuropsychiatric Interview 7.0 [MINI, [106]]. The MINI is a structured clinical interview for diagnosing psychiatric disorders.

Control twins (unaffected MZ twins) must both meet the same criteria as the unaffected co-twins of the discordant pairs. Additional exclusion criteria for healthy MZ control twin pairs are: history of psychiatric illness such as recurrent major depression, psychosis, bipolar disorder, or generalized anxiety disorder screened by the MINI International Neuropsychiatric Interview (2015), and ongoing psychotropic medication use. All participants are excluded if they report being pregnant (invited to participate at a later date), are breastfeeding (invited to participate at a later date), have a neurological disease, had brain surgery, or have magnetic materials in the body (contraindicating MRI). MZ twins who are rigorously discordant and unaffected MZ control twins who meet all of these criteria are then invited for further participation.

\section{Materials and measures Questionnaires}

Participants will complete a battery of questionnaires developed to capture a range of relevant behavioral,

Table 1 Overview of questionnaire measures used in the sample. For more detailed information of each of the instruments please refer to the Supplementary Material (1.3.1-1.3.20, Additional file 1

\begin{tabular}{|c|c|}
\hline Questionnaire & Measure \\
\hline MiniMeal-Questionnaire & General diet behaviors \\
\hline Impulsive Behavior Scale (SUPPS-P) & Impulsivity \\
\hline Active-Questionnaire (Active-Q) & Physical activity \\
\hline Eating Disorder Examination - Questionnaire (EDE-Q) & Disordered eating behavior \\
\hline Quality of Life Inventory (QOLI) & Quality of life \\
\hline Nicotine Dependency Scale & Nicotine dependence \\
\hline Hormonal, Menstrual and Reproductive History (HMRH) & Reproductive history \\
\hline Perception of Teasing Scale (POTS) & Weight and competency teasing \\
\hline Edinburgh Handedness Inventory & Handedness \\
\hline Behavioral Inhibition/Approach System (BIS/BAS) & Behavioral inhibition and approach tendencies \\
\hline Multidimensional Perfectionism Scale (MPS) & Perfectionism \\
\hline Patient Health Questionnaire (PHQ9) & Depression \\
\hline Generalized Anxiety Disorder (GAD-7) & Severity of anxiety disorder \\
\hline Autism Spectrum Quotient (AQ-10) & Position on the autism-normality continuum \\
\hline Obsessive Compulsive Inventory - Revised (OCI-R) & Compulsive behaviour \\
\hline Big Five Inventory (BFI) & Extraversion, agreeableness, consciousness, neuroticism, openness \\
\hline Online 24-Hour Recall Log Book & Nutrition intake \\
\hline Visual Analogue Scale (VAS) & Hunger and thirst \\
\hline Positive and Negative Affect Schedule (PANAS) & Positive and negative affect \\
\hline Stool and Medication Questionnaire & Gastrointestinal symptoms and medication intake \\
\hline
\end{tabular}


cognitive, personality, and psychological factors hypothesized to be relevant to risk for eating disorders (Table 1, Supplementary Material 1.2, Additional file 1).

\section{Anthropometric measures, diet, and physical activity}

Central to our investigation is the exploration of differences in anthropometric measures and body composition, diet, and physical activity among unaffected and affected twins and healthy controls. BMI is calculated from measured height (via fixed stadiometer) and weight (via calibrated digital scale). Percent body fat and lean muscle mass are measured by DXA. Physical activity is measured by the Active-Q Questionnaire (see subsection Questionnaires for more detail). Additionally, participants wear GENEActive Original accelerometers (Activinsights Ltd., UK) for a six-day period on their nondominant wrist prior to the on-site phase of the study and during the entire stay during the study. We sample vertical, anteroposterior, and mediolateral movement at a rate of $40 \mathrm{~Hz}$ to maintain accuracy at an informative level.

\section{Genetics}

Blood DNA samples from all participants will be genotyped on an appropriate chip at the time of study commencement and after standard quality control [22]. The genomic information will be used to estimate the polygenic loading for different phenotypes, including metabolic, behavioral, and psychiatric traits. The polygenic loading will be estimated by polygenic scores [65] or summary data-based best linear unbiased predictors (SBLUPs) [99] and we will investigate differences in the association of these predictors with other outcome measures. Potentially, these polygenic scores will be combined with the classical twin design [80]. For selected samples, we will consider whole genome or exome sequencing to identify de novo alterations.

\section{Epigenetics}

As monozygotic twins are nearly $100 \%$ genetically identical, the majority of genomic effects influencing differences between each twin of a twin pair will be due to epigenetic changes between the twins. To investigate these epigenetic differences between twins, we will conduct epigenome-wide association studies examining differential methylation and histone modifications [79]. We will correct for potential differences in cell type composition between the four groups by appropriate statistical models [51] and take eating disorder-specific confounders, including diet composition, medication, hormone concentrations, and underlying DNA sequence into account [45].

\section{Cognitive functions}

Participants complete a battery of neurocognitive tests both online on a laptop and by paper and pencil (Table 2). The neurocognitive battery is administered twice using alternate forms, once before (T1) and once after (T2) the $18 \mathrm{~h}$ fasting period. For more detailed description of each task, please see Supplementary Material (1.3, Additional file 1).

\section{Neuroimaging}

Participants complete a protocol of structural (T1weighted (T1W) and diffusion tensor imaging (DTI)) and functional neuroimaging sequences (resting state and four task-based scans) twice, once before (T1) and once at the end of the $18 \mathrm{~h}$ fasting period (T2, Table 3). The MRI acquisition is performed on a 3-Tesla whole body scanner (GE 750) with a 32-channel head coil. We also assess heart rate and breathing rate continuously during scanning to better control for possible artifacts during preprocessing of functional data. For more detailed description of acquisition parameters and the single tasks please refer to Supplementary Material (1.4, Additional file 1).

\section{Endocrinology and metabolism}

Blood For assessment of the endocrine and metabolic response to fasting, blood samples are taken once prior to the 18-h fast (Sample 1) and twice during the 18-h fast on the second day (Sample 2, Sample 3 Table 4).

Microdialysis The direct metabolic response in subcutaneous adipose tissue to fasting is addressed in situ by microdialysis. A probe with a tubular semipermeable membrane is placed subcutaneously in the abdominal fat after Neuroimaging T1 (hour 9 day 1) [5, 49]. A sterile Ringer's solution is continuously pumped through the dialysis tube at a flow rate of $0.5 \mu \mathrm{l} / \mathrm{min}$. The dialysate samples are collected in microvials that are changed every $30 \mathrm{~min}$. Overnight, one cumulative sample is collected between 23:00 and 6:00 to avoid disturbing the participant during sleep. The probe remains in place until after the last blood sampling on the second day. From the dialysate metabolites, including glucose, lactate pyruvate, and glycerol are analyzed for each participant repeatedly (CMA 600 Microdialysis Analyzer, CMA Microdialysis AB, Stockholm, Sweden). The data will provide us with information about glycolysis, gluconeogenesis, lipolysis with a high temporal resolution and their contribution to generate energy during the fasting period [5]. 
Table 2 Overview of tests of neurocognitive function and body image distortion applied during timepoint 1 (T1) and timepoint 2 (T2). The Set-shifting battery is based on Wolff et al. [125]; the Value-based- decision making battery (VBDM) based on Pooseh et al. [90]. The Somatomap 3D is conducted according to Ralph-Nearman et al. [94]. The Rey Osterrieth Complex Figure Test [78] was used

\begin{tabular}{|c|c|c|c|}
\hline Task & Measure & T1 & T2 \\
\hline Set-shifting & Set-shifting ability (color-shape, category switching, number-letter task) & $x$ & $x$ \\
\hline Value-based decision making battery & Delay discounting, reward sensitivity, punishment sensitivity & $x$ & $x$ \\
\hline Rey-Osterrieth Complex Figures Test & Perceptual organization \& visual memory & $x$ & $x$ \\
\hline Somatomap 3D & Body image distortion & $x$ & $x$ \\
\hline Raven's SPM & Cognitive ability & $x$ & \\
\hline
\end{tabular}

\section{Intestinal microbiota}

The stool samples are collected after the study visit at home, using OMNIgeneGut (OM-200, DNA Genotek) self-collection kits. Dietary intake for the $24 \mathrm{~h}$ before the stool sample collection is assessed via the Online 24Hour Recall Log Book (Table 1). The samples are mailed to the laboratory to extract microbial genomic DNA. In order to obtain high-resolution taxonomic and functional microbiome data, we will perform whole genome shotgun sequencing. Raw sequence data will be quality filtered and trimmed to remove bases with Phred quality scores less than 20. Downstream bioinformatics analysis will consist of: i) taxonomic composition; ii) functional composition; iii) alpha diversity (as measured by Shannon index) and beta diversity (quantified by Bray Curtis and UniFrac metrics); and iv) computing descriptive statistics and identifying groups within the data, as well as performing statistical analyses between subgroups using additional metadata, where available [86]. Since the sequencing technology and bioinformatics tools are rapidly advancing, we will utilize the most suitable methods and tools available at the time of analysis. For more detail see Supplementary Material 1.6, Additional file 1.

Table 3 Overview of sequences and acquired measures during the MRI session for timepoint 1 (T1) and timepoint 2 (T2). Established tasks were used for the investigation of reward processing [28], food processing [20], emotional face processing [95], and visual processing [66]

\begin{tabular}{llll}
\hline Scan & Measure & T1 & T2 \\
\hline Structural MRI & & & \\
T1W & T1-weighted structural brain image & $X$ & \\
DTI & Diffusion weighted brain image & & $X$ \\
Functional MRl & & & \\
Resting State & Resting state connectivity & $X$ & $X$ \\
Monetary reward task & Reward processing & $X$ & $X$ \\
Food viewing & Food cue reactivity & $X$ & $X$ \\
Fearful faces task & Emotional processing & $X$ & \\
Houses task & General visual processing & $X$ & \\
\hline
\end{tabular}

\section{Immunology}

We measure concentrations of immune-related cytokines, cell injury, and cell death markers at three different timepoints (Table 4) in plasma or serum depending on the assay (Table 5). The cytokines are representative of the function of various immune cell populations and have been previously used in studies of psychiatric disorders, including depression, bipolar disorder, and schizophrenia [41]. We also gather information on cell injury and death by measuring concentrations of nuclear molecules and general cell loss markers, such as lactate dehydrogenase (LDH).

\section{Data management \\ General data security}

All network communication between IT systems, including between participant or study operator devices, used in the study is encrypted by cryptographically strong methods as standard, if not otherwise specified. The hosting department provides central university network security services such as a central firewall and perimeter protection for the used networks. For more detail on data management please refer to Supplementary Material 1.6, Additional file 1.

\section{Data storage and business logic}

To handle administrative and research data during the collection phase of the study, we have implemented Karolinska Institutet Biobank IT, which is organizationally part of the core facility Karolinska Institutet Biobank. Data in file form are placed on the study research data disk area and indexed in a Central Research Database by an automated Study Data Management Application. The Central Research Database uses MS SQL Server technology, is only accessible by pre-specified users from selected department networks and has its own authentication scheme in addition to the department centralized directory service in the form of MS Active Directory.

All datasets will be stored in Sweden within in the described systems. All project investigators will be given access to their respective data sets and will have access 
Table 4 Overview of endocrinological parameters measured from blood samples during three different timepoints

\begin{tabular}{|c|c|c|c|c|}
\hline Analysis & $\begin{array}{l}\text { Sample } 1 \\
\text { Day } 1 \text { (T1) 3:30 pm }\end{array}$ & $\begin{array}{l}\text { Sample } 2 \\
\text { Day } 2 \\
\text { 8:00 am }\end{array}$ & $\begin{array}{l}\text { Sample } 3 \\
\text { Day } 2 \\
\text { 10:00 am }\end{array}$ & Sample type \\
\hline \multicolumn{5}{|l|}{ Hypothalamic-pituitary-adrenal axis } \\
\hline Adrenocorticotropic hormone (ACTH) & $x$ & x & x & Plasma \\
\hline Cortisol & $x$ & $x$ & $x$ & Serum \\
\hline \multicolumn{5}{|l|}{ Hypothalamic-pituitary-thyroid axis } \\
\hline Thyroid-stimulating hormone (TSH) & $(X)$ & $x$ & & Serum \\
\hline Free triiodothyronine (fT3) & $(X)$ & $x$ & & Serum \\
\hline Free thyroxine (fT4) & $(X)$ & $x$ & & Serum \\
\hline \multicolumn{5}{|l|}{ Hypothalamic-pituitary-gonadal axis } \\
\hline Follicle stimulating hormone (FSH) & & $x$ & & Serum \\
\hline Luteinizing hormone $(\mathrm{LH})$ & & $x$ & & Serum \\
\hline Dehydroepiandrosterone (DHEAS) & & $x$ & & Serum \\
\hline Sex hormone-binding globulin (SHBG) & & $x$ & & Serum \\
\hline Testosterone & & $x$ & & Serum \\
\hline \multicolumn{5}{|l|}{ Hypothalamic-pituitary-somatotropic axis } \\
\hline Insulin-like growth factor 1 (IGF-1) & $x$ & $x$ & & Serum \\
\hline Insulin-like growth factor-binding protein 1 (IGFBP-1) & $x$ & $x$ & & Serum \\
\hline Insulin-like growth factor-binding protein 3 (IGFBP-3) & $x$ & $x$ & & Serum \\
\hline \multicolumn{5}{|l|}{ Gastrointestinal hormones } \\
\hline Acyl/deacyl-ghrelin & $x$ & $x$ & $x$ & Plasma \\
\hline \multicolumn{5}{|l|}{ Adipokines } \\
\hline Adiponectin (ADIP) & $x$ & $x$ & $x$ & Serum \\
\hline Leptin & & $x$ & & Serum \\
\hline \multicolumn{5}{|l|}{ Electrolytes } \\
\hline Sodium & $x$ & & $x$ & Plasma \\
\hline Sodium & $x$ & & $x$ & Urine \\
\hline
\end{tabular}

to other sites data by request. To ensure confidentiality, data dispersed to project team members will be blinded of any identifying participant information.

\section{Web survey platform}

Confirmit is an online web survey platform service for study operators to implement and publish online web surveys and to perform data management for survey data collection. Confirmit allows us to implement surveys with advanced logical action flow, question filters, and scripted survey events. Study specific resources and collected survey data are only accessible by selected study operators. Additional PGP encryption, using a userspecific encryption key, is applied.

\section{Web site}

On the study website participants are authenticated with strong authentication methods for access to personal areas where they consent electronically to the study and access the web surveys. We use national electronic identity technology: Swedish BankID, or technology of similar capacity to perform authentication. The visual layout of the web site is made to illustrate progress through the study and the online web surveys to the participant.

\section{Online 24-h recall web tool}

The 24-h dietary recall logbook is introduced in the study through an online service by Nutrition Data Sweden AB. The 24-h recall logbook is a tool where the study participant can log nutrition intake before stool sample collection. The tool provides basic data quality protection of data entries made by the participants. Since being an online web tool, it is accessible through the internet. Study specific resources and collected survey data are only accessible by selected study operators.

\section{Statistical analyses}

The MZ co-twin-control design is a method to evaluate the effect of non-shared factors on risk for $\mathrm{AN}$, in the present study. Because MZ twins within a pair share, for all intents and purposes, $100 \%$ of their segregating genes, comparing twins discordant for AN controls for genetic and shared environmental factors. Thus, associations found between $\mathrm{AN}$ and other variables of interest 
Table 5 Overview of immunological markers estimated from blood during day 1 and day 2

\begin{tabular}{ll}
\hline Analysis & Marker \\
\hline Cytokine markers & Interleukin-1 receptor antagonist (IL-1RA) \\
& Interleukin 6 (IL-6) \\
& Interleukin 8 (IL-8) \\
& Tumor necrosis factor-a (TNF-a) \\
& Chemokine (C-C motif) ligand 5 (CCL5)/regulated on activation, normal T cell expressed and secreted (RANTES) \\
& Monocyte chemoattractant protein 1 (MCP1) \\
& High mobility group box 1 (HMGB1) \\
Interleukin-1 receptor antagonist (IL-1RA) & Double stranded deoxyribonucleic acid (dsDNA) \\
Cell death markers & Nucleosomes \\
Cell injury markers & Lactate dehydrogenase (LDH) \\
General cell injury & Aspartate transaminase (AST)/alanine transaminase (ALT) \\
Liver cell injury & Glutamate dehydrogenase (GLDH) \\
& a-fetoprotein (AFP) \\
Muscle cell injury & microRNA-122 (mRNA-122) \\
Creatine kinase (CK) & Total \& cleared cytokeratin 18 (CK-18) \\
\hline
\end{tabular}

suggest either a causal relationship, e.g., the variable of interest is a risk factor for $\mathrm{AN}$ or is a result of having $\mathrm{AN}$, or a third variable indicative of an individualspecific factor that influences both $\mathrm{AN}$ and the variable of interest.

We will first contrast twins from discordant pairs (affected vs unaffected) on the wide array of variables evaluated in this study, which assesses state factors. Given that some of the outcomes for the present study are ordinal and some are repeated measures, and we anticipate using appropriate covariates in our models, we will apply mixed models. These models account for the clustered nature of twin data (i.e., non-independence of observations) and can incorporate fixed and random effects. In addition, the distribution of the outcome variables can be specified, and covariates can be added.

Second, the concordant unaffected MZ control twins will be included in the above models to evaluate whether having an affected co-twin influences the outcome variables. Results from these analyses may provide evidence that the co-twin's affection status (an indication of familial influences of either environmental or possibly also epigenetic nature) is associated with the outcome if, e.g., the concordant unaffected twins have values or risk lower than those for the unaffected discordant twins, and these, in turn are lower than those for the affected discordant twins. Thus, these expanded models will be able to evaluate whether factors are state or trait in nature.
Those variables in which the discordant unaffected cotwins are significantly different than the affected twins will be further evaluated. In this case, the affected twins will be subdivided into those who are currently ill (state factors) and those who are recovered ("scar" effects). Pairwise comparisons will be made across the three groups: unaffected, recovered, and currently ill. "Scar" effects will be considered to be present if all three groups differ from one another (see Fig. 1; Table 6). While pairwise comparisons seem the right approach if subgroups constitute of equal (high) number of study participants, one also has to take into consideration that it might not be possible to clearly separate the group of affected twins into ill and recovered. In this case we propose a working model of using recovery status as continuous variable that can be controlled for as covariate in subsequent analyses. General covariates (e.g., illness duration, or nationality) appropriate to each domain will be entered into models. Analyses that will be across different domains (e.g., neuroimaging and endocrinology) will be handled with caution and covariates for both domains accounted for. Corrections for multiple testing will be considered within each domain to determine significance (e.g., for fMRI we will use the false discovery rate (FDR) or non-parametric permutation based approaches). Effect sizes and clinical relevance will be discussed based on the previous literature and current clinical practice. 
Table 6 Overview over expected differences/similarities between subgroups. $\neq$ describes expected differences, $=$ describes expected similarities between participants. Case Affected I = Case Twin affected from the disorder and currently ill. Case Affected $\mathrm{R}=$ Case Twin affected by the disorder and currently recovered, Case Unaffected = Monozygotic twin sister of the currently ill or recovered affected twin, Control = Healthy control twin

\begin{tabular}{|c|c|c|c|c|c|c|}
\hline Parameter & $\begin{array}{l}\text { Case Affected I vs } \\
\text { Case Affected R }\end{array}$ & $\begin{array}{l}\text { Case Affected I vs } \\
\text { Case Unaffected }\end{array}$ & $\begin{array}{l}\text { Case Affected R vs } \\
\text { Case Unaffected }\end{array}$ & $\begin{array}{l}\text { Case Affected I } \\
\text { vs Control }\end{array}$ & $\begin{array}{l}\text { Case Affected R } \\
\text { vs Control }\end{array}$ & $\begin{array}{l}\text { Case Unaffected } \\
\text { vs Control }\end{array}$ \\
\hline $\begin{array}{l}\text { State } \\
\text { Parameter }\end{array}$ & $\neq$ & $\neq$ & $=$ & $\neq$ & $=$ & $=$ \\
\hline $\begin{array}{l}\text { Trait } \\
\text { Parameter }\end{array}$ & $=$ & $=$ & $=$ & $\neq$ & $\neq$ & $\neq$ \\
\hline $\begin{array}{l}\text { Scar } \\
\text { Parameter }\end{array}$ & $=$ & $\neq$ & $\neq$ & $\neq$ & $\neq$ & $=$ \\
\hline
\end{tabular}

\section{Discussion}

CREAT is one of the first studies of AN that will allow us to parse unique environmental, genetic, and medical contributions (e.g., sequelae of undernutrition) of the disorder and therefore advances the debate of identifying underlying risk factors across different domains [88]. The comprehensive investigation optimizes the natural experiment of MZ twins who are discordant for AN. This design allows us to address several key questions related to AN risk and recovery across a broad range of relevant domains. In the following section we discuss both advantages and limitations of the current research protocol.

Adequate sample sizes are only attainable in locations with extensive twin registries, such as Sweden or Denmark. The study is demanding for participants and we have implemented a number of measures to ensure comfort and to express our deep appreciation of all participants. In addition to monetary incentives, twins are accompanied throughout the study by a dedicated research nurse and at night by specially trained nursing assistants. We have built in digital incentives and progress markers as participants work their way through questionnaires, and we are working to create a CREAT community through study branding, staying in contact with participants, and sharing results. In so doing, we hope to be able to return to twins in the future should additional research questions arise.

The specific research methods in each of the areas of the study were chosen by a panel of experts to maximize the utility of this specific data set. For example in the area of brain imaging well-validated paradigms [20, 28, $31,66,95]$ as well as state of the art statistical methods were chosen in order to ensure comparability with existing neuroimaging studies and excellent data quality. As a result of overly simplistic descriptions of the brain connectome in previous resting state research [38], we intend to apply multivariate techniques [17], graph theoretical approaches [109], and dynamic effective connectivity analyses [95], all of which offer promising tools to ask questions that go beyond simple connectivity analyses with resting state data $[11,39,40]$ and integrate results from the other study domains, e.g. metabolic and endocrinological data.

Previous neurocognitive studies have often investigated the subcomponents of (value-based) decision making within single tasks (e.g., Wisconsin card sorting task, Iowa gambling task) that are unable to further differentiate between more specific concepts such as risk aversion and loss avoidance. Hence, the task battery employed for this project [90] also provides measures for risk aversion (for gains), risk seeking (for losses), as well as loss aversion. In a similar vein, other neurocognitive abilities as well as body image distortion (i.e., Somatomap [94]) are assessed using validated state-of-the-art task batteries. We are aware of the problem of learning effects when applying these tasks repeatedly. Since the neurocognitive domain includes established and validated tasks, there is no easy solution to this problem, without possibly changing the difficulty or complexity of the task, or extending the protocol beyond what is feasible in one session. However, since the learning effects will also be visible in the $\mathrm{HC}$ twins, we will focus only on the relative differences (e.g., between the AN discordant twins accounting for differences that were also observable in $\mathrm{HC}$ twins).

Methods in the field of genetics, epigenetics, microbiome research, and immunology develop rapidly. Analytic strategies will be finalized considering the latest technologies and methodologies available at completion of data collection. However, we have taken great care to assess all potential confounds and to store and preprocess the biological materials under conditions that ensure the integrity of the materials. New publicly available databases and computational methods will help us to enrich our findings, control for population-specific effects, and identify relevant metabolic and immunological pathways [50]. Furthermore, given the deep phenotyping of CREAT, we will be able to test for associations and interactions between genetic and immunological markers, hormones, and alterations of the microbiome and potentially answer the current questions regarding the gut-brain axis [105]. 
CREAT does pose logistical challenges and results will have limitations. Firstly, our strict inclusion criteria (i.e., requiring rigorous discordance) will probably lengthen the recruitment process to ascertain eligible pairs. Secondly, although the study itself will be conducted at a single site, participant recruitment covers both Sweden and Denmark, possibly introducing subtle differences in recruitment procedures, interviewing, and translations and wordings that might affect the comparability of the data (which we will control for statistically). In long-running studies, above all at different recruitment sites, it is essential to ensure that all staff are highly trained, and procedures remain consistent across the study period (i.e., do not evidence drift). Thirdly, the targeted sample size is relatively small. Although we have power to detect relatively small effect sizes, other clinical variables may have an adverse effect on power. For example, it is not possible to predict in advance the exact proportion of participants who are actively ill versus recovered. Depending on the distribution, we may be underpowered to detect differences between these two subgroups. Furthermore, duration of illness might moderate some of the expected differences (and will therefore be treated as a covariate in statistical models). Also, including only females within a specified age range, might yield a limited picture of the disorder. This decision is practical as we were unable to identify discordant MZ male twins in the register and it is essential that we only study twins who have passed through the age of risk to ensure unaffected status. Lastly, similar to other complex studies [76], planned analyses represent a mixture of hypothesis-driven and exploratory research questions. The exploratory aims emerge from findings in the literature regarding where differences may lie in affected versus unaffected individuals.

With these challenges and limitations in mind, we have instituted multiple checks including extensive standard operating procedures (SOPs) and detailed protocols to ensure the longevity of the project and maximize the utility of the rich data that will be captured from these highly valuable sets of twins.

The twin design employed in the current study offers the opportunity to deliver a comprehensive understanding of possible alterations within genetics, epigenetics, neurocognitive function, neuroimaging, metabolism, endocrinology, microbiology, and immunology in AN by disaggregating genetic and environmental factors influencing risk for the disorder.

\section{Supplementary information}

Supplementary information accompanies this paper at https://doi.org/10. 1186/s12888-020-02903-7.

Additional file 1. Supplementary information about diagnostics and measured parameters in the study.

\section{Abbreviations}

ACTH: Adrenocorticotropic hormone; ADIP: Adiponectin; AFP: a-fetoprotein; ALT: Alanine transaminase; AN: Anorexia nervosa; AQ-10: Autism spectrum disorder; AST: Aspartate transaminase; BFI: Big five inventory; BIS/

BAS: Behavioral inhibition and behavioural activation system; BMI: Body-mass index; BOLD: Blood oxygenation level-dependent; CCL5: Chemokine (C-C

motif) ligand; CK: Creatine kinase; CREAT: Comprehensive risk evaluation for anorexia nervosa in twins; CRP: C-reactive protein; DHEA

S: Dehydroepiandrosterone; dsDNA: Double stranded deoxyribonucleic acid; DSM-V: Diagnostic and Statistical Manual of Mental Disorders; DTI: Diffusion tensor imaging; DTR: Danish twin registry; DXA: Dual X-ray absorptiometry;

ED: Eating disorder; ED100K: Eating disorder diagnostic online questionnaire; EDE: Eating Disorder Examination; EDE-Q: Eating Disorder Examination Questionnaire; fMRI: Functional magnetic resonance imaging; FSH: Follicle stimulating hormone; FT3: Free triiodothyronine; FT4: Free thyroxine; GAD7: General anxiety disorder questionnaire; GLDH: Glutamate dehydrogenase; GM: Grey matter; GWAS: Genome-wide association study; HMGB: High mobility group; HMRH: Hormonal, menstrual and reproductive history; IGF: Insulin-like growth factor; IGFBP: Insulin-like growth factor-binding protein; IL: Interleukin; IL-1RA: Interleukin-1 receptor antagonist; IQ: Intelligence quotient; LDH: Lactate dehydrogenase; LH: Luteinizing hormone; MCP: Monocyte chemoattractant protein; MINI: Mini International Neuropsychiatric Interview; MPS: Multidimensional perfectionism scale; MR(I): Magnetic resonance (imaging); MZ: Monozygotic; OCl-R: Obsessive compulsive inventory - revised; PANAS: Positive and negative affect scale; PHQ9: Patient health questionnaire; POTS: Perception of teasing scale; QOLI: Quality of life inventory; Ravens SPM: Raven's progressive matrices und vocabulary scales; ROI: Region of interest; SBLUP: summary data-based best linear unbiased predictors; SCID: Structured Clinical Interview for DSM-5; SD: Standard Deviation; SHGB: Sex hormone-binding globulin; SPM: Statistical parametric mapping software; STR: Swedish twin registry; SUPPS-P: Impulsive behaviour scale; T1: Timepoint 1; T2: Timepoint 2; TNFa: Tumor necrosis factor a; TSH: Thyroid-stimulating hormone; VAS: Visual analogue scale; VBDM: Value based decision making; WM: White matter

\section{Acknowledgements}

We would like to thank all the participants for their willingness to help in this study. We would further like to express our gratitude to all junior researchers and student workers for their assistance with diagnostic interviews, data collection, and quality checks. We acknowledge The Swedish and Danish Twin Registry for access to data. The Swedish Twin Registry is managed by Karolinska Institutet and receives funding through the Swedish Research Council (VR Dnr: 2017-00641), and the Danish Twin Registry is managed by the University of South Denmark.

\section{Authors' contributions}

$A G, C B, E W, L M T$ were responsible for conceptualization and design of the study. CB, JMS were responsible for funding in Sweden and Denmark. CB, $A G, E W, L B$ (and others) created and piloted the study protocol. AG, MS, SE, $L B, I B, E W$, JDF were responsible for the setup and analysis plans of the neuroimaging component of the study. MS, LB, MSch, AS helped with data acquisition of the neuroimaging data. AG, SE, MS, JDF designed the neurocognitive test battery. CW, $\mathrm{AA}, \mathrm{CB}, \mathrm{RN}$ designed the microbiome component of the study. $\mathrm{CH}, \mathrm{RN}, \mathrm{CB}$ conceptualized the setup of the microdialysis and endocrinological investigations. $A B, J P, R N$ helped with the data acquisition of the microdialysis section. $\mathrm{BF}, \mathrm{CH}, \mathrm{VL}, \mathrm{SE}, \mathrm{CB}$ helped with the design of genetics and epigenetics and immunological components of the study. AG, BF, SE, EW, AB, JP, LMT, CB helped with designing the recruitment procedures, clinical diagnostics, interviews, and scheduling of participants. AG, LMT, EW, CB designed the format of the questionnaire battery for the current study. JZ, AS implemented the data storage and analysis pipelines for the current project. JMS, EVR, KCH were responsible for recruitment, coordination, conducting diagnostic interviews and translations in Denmark. MS, SE, CH, AA, AS, CB, LMT, AG made substantial contributions to the manuscript. All authors reviewed and approved the current manuscript.

\section{Funding}

This work is funded by the Swedish Research Council (VR Dnr: 538-20138864) as well as the German Research Society (DFG: EH 367/7-1). The funding body was not involved in the design of the study, data collection, 
analysis and interpretation of data, as well as in writing the manuscript. Open Access funding enabled and organized by Projekt DEAL.

\section{Availability of data and materials}

Not applicable.

\section{Ethics approval and consent to participate}

Ethical approvals were granted by the Regional Ethical Review Board in Stockholm (Dnr 2015/1479-31/2) and in Denmark, by the Regional Ethics Review Board in Hillerod (H-17004363, 24 August 2017). All Changes to the protocol are sent as amendments to the respective Ethical Review Board for approval. Consent to participate is given in written form (Denmark) and electronically (Sweden, see Data Management section) from all participants after initial contact.

\section{Consent for publication}

Not applicable.

\section{Competing interests}

CM Bulik reports: Shire (grant recipient, Scientific Advisory Board member); Idorsia (consultant) Pearson (author, royalty recipient). Other authors report no competing interests.

\section{Author details}

${ }^{1}$ Division of Psychological and Social Medicine and Developmental Neurosciences, Faculty of Medicine, Technische Universität Dresden, Fetscherstraße 74, 01307 Dresden, Germany. ²Department of Medical Epidemiology and Biostatistics, Karolinska Institutetet, Nobels väg 12A, 17165 Stockholm, Solna, Sweden. ${ }^{3}$ Department of Psychiatry, Harvard Medical School, Boston, MA, USA. ${ }^{4}$ Eating Disorders Clinical and Research Program, Massachusetts General Hospital, Boston, MA, USA. ${ }^{5}$ Centre for Psychiatry Research, Department of Clinical Neuroscience, Karolinska Institutet, Stockholm, Sweden. ${ }^{6}$ Stockholm Health Care Services, Region Stockholm,

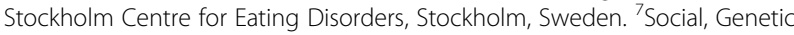
\& Developmental Psychiatry Centre, Institute of Psychiatry, Psychology \& Neuroscience, King's College London, London, UK. ${ }^{8}$ UK National Institute for Health Research (NIHR) Biomedical Research Centre (BRC), South London and Maudsley NHS Foundation Trust, London, UK. ${ }^{9}$ National Centre for Register-based Research, Aarhus Business and Social Sciences, Aarhus University, Aarhus, Denmark. ${ }^{10}$ Department of Clinical Neuroscience, Karolinska Institutet, Stockholm, Sweden. ${ }^{11}$ Department of Clinical Medicine, University of Copenhagen, Copenhagen, Denmark. ${ }^{12}$ Eating Disorder Research Unit, Mental Health Center Ballerup, Ballerup, Denmark. ${ }^{13}$ Department of Women's and Children's Health, Karolinska Institutet, Stockholm, Sweden. ${ }^{14}$ Department of Psychiatry and Biobehavioral Sciences, University of California Los Angeles, Los Angeles, CA, USA. ${ }^{15}$ Department of Psychiatry, University of North Carolina at Chapel Hill, Chapel Hill, NC, USA. ${ }^{16}$ Department of Nutrition, University of North Carolina at Chapel Hill, Chapel Hill, NC, USA.

\section{Received: 1 May 2020 Accepted: 29 September 2020}

Published online: 14 October 2020

\section{References}

1. Adoue C, Jaussent I, Olié E, Beziat S, Van den Eynde F, Courtet P, Guillaume S. A further assessment of decision-making in anorexia nervosa. Eur Psychiatry. 2015;30(1):121-7.

2. Alegría-Torres JA, Baccarelli A, Bollati V. Epigenetics and lifestyle. Epigenomics. 2011;3(3):267-77.

3. American Psychiatric Association. The American Psychiatric Association Practice Guidelines for the Psychiatric Evaluation of Adults (third edition). Am Psychiatric Assoc. 2015; https://doi.org/10.1176/appi.books. 9780890426760

4. Armougom F, Henry M, Vialettes B, Raccah D, Raoult D. Monitoring bacterial community of human gut microbiota reveals an increase in Lactobacillus in obese patients and methanogens in anorexic patients. PLoS One. 2009;4(9): e7125.

5. Arner P, Bolinder J. Microdialysis of adipose tissue. J Intern Med. 1991;230(4): 381-6.

6. Bardone-Cone AM, Harney MB, Maldonado CR, Lawson MA, Robinson DP, Smith $\mathrm{R}$, et al. Defining recovery from an eating disorder: Conceptualization, validation, and examination of psychosocial functioning and psychiatric comorbidity. Behav Res Ther. 2010;48(3):194-202. https://doi.org/10.1016/j. brat.2009.11.001.

7. Benau EM, Orloff NC, Janke EA, Serpell L, Timko CA. A systematic review of the effects of experimental fasting on cognition. Appetite. 2014;77:52-61 https://doi.org/10.1016/j.appet.2014.02.014.

8. Bernardoni F, Bernhardt N, Pooseh S, King JA, Geisler D, Ritschel F, Boehm I, Seidel M, Roessner V, Smolka MN, Ehrlich S. Metabolic state and value-based decision-making in acute and recovered female patients with anorexia nervosa. J Psychiatry Neurosci. 2020;45(3):190031.

9. Bernardoni F, King JA, Geisler D, Birkenstock J, Tam FI, Weidner K, Roessner $\checkmark$, White T, Ehrlich S. Nutritional status affects cortical folding: lessons learned from anorexia nervosa. Biol Psychiatry. 2018;84(9):692-701 https:// doi.org/10.1016/j.biopsych.2018.05.008.

10. Bernardoni F, King JA, Geisler D, Stein E, Jaite C, Nätsch D, Tam Fl, Boehm I, Seidel M, Roessner V, Ehrlich S. Weight restoration therapy rapidly reverses cortical thinning in anorexia nervosa: A longitudinal study. Neurolmage. 2016;130:214-22 https://doi.org/10.1016/j. neuroimage.2016.02.003

11. Boehm I, Geisler D, King JA, Ritschel F, Seidel M, Deza Araujo Y, Petermann J, Lohmeier H, Weiss J, Walter M, Roessner V, Ehrlich S. Increased resting state functional connectivity in the fronto-parietal and default mode network in anorexia nervosa. Front Behav Neurosci. 2014;8:346 https://doi. org/10.3389/fnbeh.2014.00346

12. Boehm I, Geisler D, Tam F, King JA, Ritschel F, Seidel M, Bernardoni F, Murr J, Goschke T, Calhoun VD, Roessner V, Ehrlich S. Partially restored restingstate functional connectivity in women recovered from anorexia nervosa. J Psychiatry Neurosci. 2016;41(3):150259.

13. Bolton HM, Burgess PW, Gilbert SJ, Serpell L. Increased set shifting costs in fasted healthy volunteers. PLoS One. 2014;9(7) https://doi.org/10.1371/ journal.pone.0101946.

14. Borgo F, Riva A, Benetti A, Casiraghi MC, Bertelli S, Garbossa S, Anselmetti S, Scarone S, Pontiroli AE, Morace G. Microbiota in anorexia nervosa: the triangle between bacterial species, metabolites and psychological tests. PLoS One. 2017;12(6):e0179739.

15. Breithaupt L, Köhler-Forsberg O, Larsen JT, Benros ME, Thornton LM, Bulik CM, Petersen L. Association of Exposure to infections in childhood with risk of eating disorders in adolescent girls. JAMA Psychiatry. 2019; https://doi. org/10.1001/jamapsychiatry.2019.0297.

16. Bulik CM. Towards a science of eating disorders: replacing myths with realities: the fourth Birgit Olsson lecture. Nordic J Psychiatry. 2016;70(3):224-30.

17. Calhoun VD, Kiehl KA, Pearlson GD. Modulation of temporally coherent brain networks estimated using ICA at rest and during cognitive tasks. Hum Brain Mapp. 2008;29(7):828-38 https://doi.org/10.1002/hbm.20581.

18. Cani PD, Delzenne NM. The role of the gut microbiota in energy metabolism and metabolic disease. Curr Pharm Des. 2009;15(13):1546-58 https://doi.org/10.2174/138161209788168164.

19. Capuron L, Miller AH. Immune system to brain signaling: Neuropsychopharmacological implications. Pharmacol Ther. 2011;130(2):226-38.

20. Charbonnier L, van Meer F, Johnstone AM, Crabtree D, Buosi W, Manios Y, Androutsos O, Giannopoulou A, Viergever MA, Smeets PAM. Effects of hunger state on the brain responses to food cues across the life span. Neurolmage. 2018:171:246-55 https://doi.org/10.1016/j.neuroimage.2018.01.012.

21. Chesney E, Goodwin GM, Fazel S. Risks of all-cause and suicide mortality in mental disorders: A meta-review. World Psychiatry. 2014;13(2):153-60 https://doi.org/10.1002/wps.20128.

22. Coleman JR, Euesden J, Patel H, Folarin AA, Newhouse S, Breen G. Quality control, imputation and analysis of genome-wide genotyping data from the Illumina HumanCoreExome microarray. Briefings Functional Genomics. 2015: 15(4):298-304

23. Cooper Z, Fairburn C. The eating disorder examination: A semi-structured interview for the assessment of the specific psychopathology of eating disorders. Int J Eat Disord. 1987;6(1):1-8.

24. Cowdrey FA, Filippini N, Park RJ, Smith SM, McCabe C. Increased resting state functional connectivity in the default mode network in recovered anorexia nervosa: resting state functional connectivity in the DMN in recovered AN. Hum Brain Mapp. 2014;35(2):483-91 https://doi.org/10.1002/ hbm.22202.

25. Dalton B, Bartholdy S, Robinson L, Solmi M, Ibrahim MA, Breen G, Schmidt $\mathrm{U}$, Himmerich $\mathrm{H}$. A meta-analysis of cytokine concentrations in eating disorders. J Psychiatr Res. 2018. 
26. Decker JH, Figner B, Steinglass JE. On weight and waiting: delay discounting in anorexia nervosa pretreatment and posttreatment. Biol Psychiatry. 2015; 78(9):606-14.

27. Dinan TG, Cryan JF. Gut-brain axis in 2016: brain-gut-microbiota axis mood, metabolism and behaviour. Nature Reviews Gastroenterol Hepatol. 2017;14(2):69-70 https://doi.org/10.1038/nrgastro.2016.200.

28. Ehrlich S, Geisler D, Ritschel F, King JA, Seidel M, Boehm I, Breier M, Clas S, Weiss J, Marxen M, Smolka MN, Roessner V, Kroemer NB. Elevated cognitive control over reward processing in recovered female patients with anorexia nervosa. J Psychiatry Neurosci. 2015;40(4):307.

29. Emilsson L, Lindahl B, Koster M, Lambe M, Ludvigsson JF. Review of 103 Swedish healthcare quality registers. Int J Epidemiol. 2015;44:174.

30. Fairburn CG, Beglin SJ. Assessment of eating disorders: Interview or selfreport questionnaire? Int J Eat Disord. 1994;16(4):363-70.

31. Feusner JD, Hembacher E, Moller H, Moody TD. Abnormalities of object visual processing in body dysmorphic disorder. Psychol Med. 2011;41(11): 2385-97.

32. First MB, Williams JB. SCID-5-CV: structured clinical interview for DSM-5 disorders: clinician version: American Psychiatric Association Publishing; 2016.

33. Frank GKW, DeGuzman MC, Shott ME. Motivation to eat and not to eat-the psycho-biological conflict in anorexia nervosa. Physiol Behav. 2019; https://doi.org/10.1016/j.physbeh.2019.04.007.

34. Franko DL, Tabri N, Keshaviah A, Murray HB, Herzog DB, Thomas JJ, Coniglio K, Keel PK, Eddy KT. Predictors of long-term recovery in anorexia nervosa and bulimia nervosa: data from a 22-year longitudinal study. J Psychiatr Res. 2018;96:183-8

35. Frith U. Autism: explaining the enigma: Blackwell Publishing; 2003.

36. Fung TC, Olson CA, Hsiao EY. Interactions between the microbiota, immune and nervous systems in health and disease. Nat Neurosci. 2017;20(2):145-55 https://doi.org/10.1038/nn.4476

37. Galimberti E, Fadda E, Cavallini MC, Martoni RM, Erzegovesi S, Bellodi L. Executive functioning in anorexia nervosa patients and their unaffected relatives. Psychiatry Res. 2013;208(3):238-44

38. Gaudio S, Wiemerslage L, Brooks SJ, Schiöth HB. A systematic review of resting-state functional-MRI studies in anorexia nervosa: evidence for functional connectivity impairment in cognitive control and visuospatial and body-signal integration. Neurosci Biobehav Rev. 2016;71:578-89 https:// doi.org/10.1016/j.neubiorev.2016.09.032.

39. Geisler D, Borchardt V, Boehm I, King JA, Tam Fl, Marxen M, Biemann R, Roessner V, Walter M, Ehrlich S. Altered global brain network topology as a trait marker in patients with anorexia nervosa. Psychol. Med. 2020;50(1):10715. https://doi.org/10.1017/S0033291718004002.

40. Geisler D, Borchardt V, Lord AR, Boehm I, Ritschel F, Zwipp J, Clas S, King JA, Wolff-Stephan S, Roessner V, Walter M, Ehrlich S. Abnormal functional global and local brain connectivity in female patients with anorexia nervosa. J Psychiatry Neurosci. 2016;41(1):6-15

41. Goldsmith DR, Rapaport MH, Miller BJ. A meta-analysis of blood cytokine network alterations in psychiatric patients: comparisons between schizophrenia, bipolar disorder and depression. Mol Psychiatry. 2016;21(12): 1696.

42. Hebebrand J, Remschmidt H. Anorexia nervosa viewed as an extreme weight condition: genetic implications. Hum Genet. 1995;95(1):1-11.

43. Hedman A, Breithaupt L, Hübel C, Thornton LM, Tillander A, Norring C, Birgeg \aard A, Larsson $H$, Ludvigsson JF, Sävendahl L. Bidirectional relationship between eating disorders and autoimmune diseases. J Child Psychol Psychiatry. 2019;60(7):803-12.

44. Holsen LM, Lawson EA, Blum J, Ko E, Makris N, Fazeli PK, Klibanski A, Goldstein JM. Food motivation circuitry hypoactivation related to hedonic and nonhedonic aspects of hunger and satiety in women with active anorexia nervosa and weight-restored women with anorexia nervosa. J Psychiatry Neurosci. 2012;37(5):322-32 https://doi.org/10.1503/jpn.110156.

45. Hübel C, Leppä V, Breen G, Bulik CM. Rigor and reproducibility in genetic research on eating disorders. Int J Eat Disord. 2018a;51(7):593-607 https:// doi.org/10.1002/eat.22896.

46. Hübel C, Marzi SJ, Breen G, Bulik CM. Epigenetics in eating disorders: A systematic review. Mol Psychiatry. 2018b;1.

47. Hübel C, Yilmaz Z, Schaumberg KE, Breithaupt L, Hunjan A, Horne E, GarcíaGonzález J, O'Reilly PF, Bulik CM, Breen G. Body composition in anorexia nervosa: meta-analysis and meta-regression of cross-sectional and longitudinal studies. Int J Eat Disord. 2019;52(11):1205-23.
48. Jackson MA, Verdi S, Maxan M-E, Shin CM, Zierer J, Bowyer RCE, Martin T, Williams FMK, Menni C, Bell JT, Spector TD, Steves CJ. Gut microbiota associations with common diseases and prescription medications in a population-based cohort. Nat Commun. 2018;9(1):2655 https://doi.org/10. 1038/s41467-018-05184-7.

49. Jadhav SB, Khaowroongrueng $\mathrm{V}$, Derendorf $\mathrm{H}$. Microdialysis of large molecules. J Pharm Sci. 2016;105(11):3233-42.

50. Jardillier R, Chatelain F, Guyon L. Bioinformatics methods to select prognostic biomarker genes from large scale datasets: A review. Biotechnol J. 2018;13(12):e1800103 https://doi.org/10.1002/biot.201800103.

51. Jones MJ, Moore SR, Kobor MS. Principles and challenges of applying epigenetic epidemiology to psychology. Annu Rev Psychol. 2018;69(1):45985.

52. Kamel A, Norgren S, Persson B, Marcus C. Insulin induced hypoglycaemia: comparison of glucose and glycerol concentrations in plasma and microdialysate from subcutaneous adipose tissue. Arch Dis Child. 1999;80(1): 42-5.

53. Kaye WH, Wierenga CE, Bailer UF, Simmons AN, Bischoff-Grethe A. Nothing tastes as good as skinny feels: the neurobiology of anorexia nervosa. Trends Neurosci. 2013;36(2):110-20 https://doi.org/10.1016/j.tins.2013.01.003.

54. Keel PK, Klump KL, Miller KB, McGue M, lacono WG. Shared transmission of eating disorders and anxiety disorders. Int J Eating Disorders. 2005;38(2):99105 https://doi.org/10.1002/eat.20168.

55. King JA, Frank GK, Thompson PM, Ehrlich S. Structural neuroimaging of anorexia nervosa: future directions in the quest for mechanisms underlying dynamic alterations. Biol Psychiatry. 2017;83(3):224-34.

56. King JA, Geisler D, Bernardoni F, Ritschel F, Böhm I, Seidel M, Mennigen E, Ripke S, Smolka MN, Roessner V, Ehrlich S. Altered neural efficiency of decision making during temporal reward discounting in anorexia nervosa. J Am Acad Child Adolesc Psychiatry. 2016; https://doi.org/10.1016/j.jaac.2016. 08.005 .

57. King JA, Geisler D, Ritschel F, Boehm I, Seidel M, Roschinski B, Soltwedel L, Zwipp J, Pfuhl G, Marxen M, Roessner V, Ehrlich S. Global cortical thinning in acute anorexia nervosa normalizes following long-term weight restoration. Biol Psychiatry. 2015;77(7):624-32 https://doi.org/10.1016/j.biopsych.2014.09. 005.

58. Kishi T, Elmquist JK. Body weight is regulated by the brain: A link between feeding and emotion. Mol Psychiatry. 2005;10(2):132-46.

59. Kleiman SC, Watson HJ, Bulik-Sullivan EC, Huh EY, Tarantino LM, Bulik CM, Carroll IM. The intestinal microbiota in acute anorexia nervosa and during renourishment: relationship to depression, anxiety, and eating disorder psychopathology. Psychosom Med. 2015;77(9):969.

60. Kringelbach ML, Stein A, van Hartevelt TJ. The functional human neuroanatomy of food pleasure cycles. Physiol Behav. 2012;106(3):307-16 https://doi.org/10.1016/j.physbeh.2012.03.023.

61. Lang K, Roberts M, Harrison A, Lopez C, Goddard E, Khondoker M, Treasure J, Tchanturia K. Central coherence in eating disorders: A synthesis of studies using the Rey Osterrieth complex figure test. PLoS One. 2016a;11(11).

62. Lang K, Stahl D, Espie J, Treasure J, Tchanturia K. Set shifting in children and adolescents with anorexia nervosa: an exploratory systematic review and meta-analysis. Int J Eat Disord. 2014;47(4):394-9 https://doi.org/10.1002/eat. 22235.

63. Lang K, Treasure J, Tchanturia K. Is inefficient cognitive processing in anorexia nervosa a familial trait? A neuropsychological pilot study of mothers of offspring with a diagnosis of anorexia nervosa. World J Biological Psychiatry. 2016b;17(4):258-65.

64. Lawson EA, Holsen LM, DeSanti R, Santin M, Meenaghan E, Herzog DB, Goldstein JM, Klibanski A. Increased hypothalamic-pituitary-adrenal drive is associated with decreased appetite and hypoactivation of food-motivation neurocircuitry in anorexia nervosa. Eur J Endocrinol. 2013;169(5):639-47 https://doi.org/10.1530/EJE-13-0433.

65. Lewis CM, Vassos E. Prospects for using risk scores in polygenic medicine. Genome Medicine. 2017;9(1):96.

66. Li W, Lai TM, Bohon C, Loo SK, McCurdy D, Strober M, Bookheimer S, Feusner J. Anorexia nervosa and body dysmorphic disorder are associated with abnormalities in processing visual information. Psychol Med. 2015a; 45(10):2111-22 https://doi.org/10.1017/S0033291715000045.

67. Li W, Lai TM, Loo SK, Strober M, Mohammad-Rezazadeh I, Khalsa S, Feusner J. Aberrant early visual neural activity and brain-behavior relationships in anorexia nervosa and body dysmorphic disorder. Front Hum Neurosci. 2015b;9 https://doi.org/10.3389/fnhum.2015.00301. 
68. Lichtenstein P, Faire UD, Floderus B, Svartengren M, Svedberg P, Pedersen NL. The Swedish twin registry: A unique resource for clinical, epidemiological and genetic studies. J Intern Med. 2002;252(3):184-205 https://doi.org/10.1046/j.1365-2796.2002.01032.x.

69. Lichtenstein P, Sullivan PF, Cnattingius S, Gatz M, Johansson S, Carlström E, Björk C, Svartengren M, Wolk A, Klareskog L, de Faire U, Schalling M, Palmgren J, Pedersen NL. The Swedish twin registry in the third millennium: an update. Twin Research and Human Genetics. 2006;9(6):875-82 https:// doi.org/10.1375/183242706779462444.

70. Ligthart S, Vaez A, Võsa U, Stathopoulou MG, De Vries PS, Prins BP, Van der Most PJ, Tanaka T, Naderi E, Rose LM. Genome analyses of > 200,000 individuals identify 58 loci for chronic inflammation and highlight pathways that link inflammation and complex disorders. Am J Hum Genet. 2018;103(5):691-706.

71. Lindner SE, Fichter MM, Quadflieg N. Set-shifting and its relation to clinical and personality variables in full recovery of anorexia nervosa. Eur Eat Disord Rev. 2014;22(4):252-9.

72. Ludvigsson JF, Almqvist C, Bonamy A-KE, Ljung R, Michaëlsson K, Neovius M, Stephansson O, Ye W. Registers of the Swedish total population and their use in medical research. Eur J Epidemiol. 2016;31(2):125-36.

73. Lynge E, Sandegaard JL, Rebolj M. The Danish National Patient Register. Scand J Public Health. 2011;39(7 Suppl):30-3 https://doi.org/10.1177/ 1403494811401482

74. Mack I, Cuntz U, Grämer C, Niedermaier S, Pohl C, Schwiertz A, Zimmermann $\mathrm{K}$, Zipfel S, Enck P, Penders J. Weight gain in anorexia nervosa does not ameliorate the faecal microbiota, branched chain fatty acid profiles, and gastrointestinal complaints. Sci Rep. 2016;6:26752.

75. Magnusson PKE, Almqvist C, Rahman I, Ganna A, Viktorin A, Walum H, Halldner L, Lundström S, Ullén F, Långström N, Larsson H, Nyman A, Gumpert CH, Råstam M, Anckarsäter H, Cnattingius S, Johannesson M, Ingelsson $\mathrm{E}$, Klareskog $\mathrm{L}$, et al. The Swedish twin registry: establishment of a biobank and other recent developments. Twin Res Human Genetics. 2013; 16(1):317-29 https://doi.org/10.1017/thg.2012.104.

76. Mascarell Maričić, L., Walter, H., Rosenthal, A., Ripke, S., Quinlan, E. B., Banaschewski, T., Barker, G. J., Bokde, A. L. W., Bromberg, U., Büchel, C. Desrivières, S., Flor, H., Frouin, V., Garavan, H., Itterman, B., Martinot, J.-L., Martinot, M.-L. P., Nees, F., Orfanos, D. P.., ... IMAGEN consortium. (2020). The IMAGEN study: A decade of imaging genetics in adolescents. Mol Psychiatry https://doi.org/10.1038/s41380-020-0822-5.

77. McFadden KL, Tregellas JR, Shott ME, Frank GKW. Reduced salience and default mode network activity in women with anorexia nervosa. J Psychiatry Neurosci. 2014;39(3):178-88.

78. Meyers JE, Meyers KR. Rey complex figure test under four different administration procedures. Clin Neuropsychol. 1995;9(1):63-67.

79. Mill J, Heijmans BT. From promises to practical strategies in epigenetic epidemiology. Nat Rev Genet. 2013;14(8):585.

80. Minică CC, Dolan CV, Boomsma DI, de Geus E, Neale MC. Extending causality tests with genetic instruments: an integration of Mendelian randomization with the classical twin design. Behav Genet. 2018:1-13.

81. Morita C, Tsuji H, Hata T, Gondo M, Takakura S, Kawai K, Yoshihara K, Ogata K, Nomoto K, Miyazaki K. Gut dysbiosis in patients with anorexia nervosa. PLoS One. 2015;10(12):e0145274.

82. Mörkl S, Lackner S, Müller W, Gorkiewicz G, Kashofer K, Oberascher A, Painold A, Holl A, Holzer P, Meinitzer A. Gut microbiota and body composition in anorexia nervosa inpatients in comparison to athletes, overweight, obese, and normal weight controls. Int J Eat Disord. 2017; 50(12):1421-31.

83. Morris A. Microbiota alters behaviour. Nature Reviews. Endocrinol. 2018; 14(9):502 https://doi.org/10.1038/s41574-018-0061-X.

84. Mors O, Perto GP, Mortensen PB. The Danish psychiatric central research register. Scand J Public Health. 2011;39(7 Suppl):54-7 https://doi.org/10. 1177/1403494810395825.

85. O'Hara CB, Campbell IC, Schmidt U. A reward-centred model of anorexia nervosa: A focussed narrative review of the neurological and psychophysiological literature. Neurosci Biobehav Rev. 2015;52:131-52 https://doi.org/10.1016/j.neubiorev.2015.02.012.

86. Österlund T, Jonsson V, Kristiansson E. HirBin: High-resolution identification of differentially abundant functions in metagenomes. BMC Genomics. 2017; 18(1):316. https://doi.org/10.1186/s12864-017-3686-6.

87. Pender S, Gilbert SJ, Serpell L. The neuropsychology of starvation: setshifting and central coherence in a fasted nonclinical sample. PLoS One. 2014;9(10) https://doi.org/10.1371/journal.pone.0110743.
88. Phillipou A, Musić S, Lee Rossell S. A biopsychosocial proposal to progress the field of anorexia nervosa. Australian New Zealand J Psychiatry. 2019; 53(12):1145-7.

89. Phillipou A, Rossell SL, Castle DJ. Anorexia nervosa or starvation? Eur J Neurosci. 2018;48(11):3317-8.

90. Pooseh S, Bernhardt N, Guevara A, Huys QJ, Smolka MN. Value-based decision-making battery: A Bayesian adaptive approach to assess impulsive and risky behavior. Behav Res Methods. 2018;50(1):236-49.

91. Qin Y, Wade PA. Crosstalk between the microbiome and epigenome: messages from bugs. J Biochem. 2018;163(2):105-12 https://doi.org/10.1093/ $\mathrm{jb} / \mathrm{mv} \times 080$.

92. Raevuori A, Haukka J, Vaarala O, Suvisaari JM, Gissler M, Grainger M, Linna MS, Suokas JT. The increased risk for autoimmune diseases in patients with eating disorders. PLoS One. 2014;9(8):e104845 https://doi.org/10.1371/ journal.pone.0104845.

93. Raevuori A, Keski-Rahkonen A, Hoek HW, Sihvola E, Rissanen A, Kaprio J. Lifetime anorexia nervosa in young men in the community: five cases and their co-twins. Int J Eating Disorders. 2008;41(5):458-63 https://doi.org/10. 1002/eat.20525.

94. Ralph-Nearman C, Arevian AC, Puhl M, Kumar R, Villaroman D, Suthana N, Feusner JD, Khalsa SS. A novel Mobile tool (Somatomap) to assess body image perception pilot tested with fashion models and nonmodels: cross-sectional study. JMIR Mental Health. 2019;6(10):e14115. https://doi.org/10.2196/14115,

95. Rangaprakash D, Bohon C, Lawrence KE, Moody T, Morfini F, Khalsa SS, Strober M, Feusner JD. Aberrant dynamic connectivity for fear processing in anorexia nervosa and body Dysmorphic disorder. Front Psychiatry. 2018;9: $273 \mathrm{https}: / /$ doi.org/10.3389/fpsyt.2018.00273.

96. Ritschel F, King JA, Geisler D, Flohr L, Neidel F, Boehm I, Seidel M, Zwipp J, Ripke S, Smolka MN, Roessner V, Ehrlich S. Temporal delay discounting in acutely ill and weight-recovered patients with anorexia nervosa. Psychol Med. 2015;45(6):1229-39 https://doi.org/10.1017/50033291714002311.

97. Roberts ME, Tchanturia K, Treasure JL. Exploring the neurocognitive signature of poor set-shifting in anorexia and bulimia nervosa. J Psychiatr Res. 2010;44(14):964-70.

98. Roberts ME, Tchanturia K, Treasure JL. Is attention to detail a similarly strong candidate endophenotype for anorexia nervosa and bulimia nervosa? World J Biological Psychiatry. 2013;14(6):452-63.

99. Robinson MR, Kleinman A, Graff M, Vinkhuyzen AA, Couper D, Miller MB, Peyrot WJ, Abdellaoui A, Zietsch BP, Nolte IM. Genetic evidence of assortative mating in humans. Nat Hum Behav. 2017;1(1):0016.

100. Scaife JC, Godier LR, Filippini N, Harmer CJ, Park RJ. Reduced resting-state functional connectivity in current and recovered restrictive anorexia nervosa. Front Psychiatry. 2017;8:30 https://doi.org/10.3389/fpsyt.2017.00030.

101. Schorr M, Miller KK. The endocrine manifestations of anorexia nervosa: mechanisms and management. Nat Rev Endocrinol. 2017;13(3):174.

102. Schwensen HF, Kan C, Treasure J, Høiby N, Sjögren M. A systematic review of studies on the faecal microbiota in anorexia nervosa: future research may need to include microbiota from the small intestine. Eat Weight Disorders. 2018;23(4):399-418 https://doi.org/10.1007/s40519-018-0499-9.

103. Seidel M, King JA, Ritschel F, Boehm I, Geisler D, Bernardoni F, Beck M, Pauligk S, Biemann R, Strobel A, Goschke T, Walter H, Roessner V, Ehrlich S. Processing and regulation of negative emotions in anorexia nervosa: an fMRI study. Neurolmage Clin. 2018:18:1-8 https://doi.org/10.1016/..nicl.2017.12.035.

104. Seitz J, Herpertz-Dahlmann B, Konrad K. Brain morphological changes in adolescent and adult patients with anorexia nervosa. J Neural Transm. 2016; https://doi.org/10.1007/s00702-016-1567-9.

105. Seitz J, Trinh S, Herpertz-Dahlmann B. The microbiome and eating disorders. Psychiatr Clin. 2019;42(1):93-103.

106. Sheehan DV, Sheehan KH, Shytle RD, Janavs J, Bannon Y, Rogers JE, Milo KM, Stock SL, Wilkinson B. Reliability and validity of the Mini international neuropsychiatric interview for children and adolescents (MINI-KID). J Clin Psychiatry. 2010;71(3):313-26 https://doi.org/10.4088/JCP.09m05305whi.

107. Skytthe A, Christiansen L, Kyvik KO, Bødker FL, Hvidberg L, Petersen I, Nielsen MMF, Bingley P, Hjelmborg J, Tan Q, Holm NV, Vaupel JW, McGue M, Christensen K. The Danish twin registry: linking surveys, national registers, and biological information. Twin Res Human Genetics. 2013;16(1):104-11 https://doi.org/10.1017/thg.2012.77.

108. Skytthe A, Kyvik KO, Holm NV, Christensen K. The Danish twin registry. Scand J Public Health. 2011;39(7 Suppl):75-8 https://doi.org/10.1177/ 1403494810387966.

109. Sporns O. Networks of the brain: MIT Press; 2010. 
110. Steinglass JE, Figner B, Berkowitz S, Simpson HB, Weber EU, Walsh BT. Increased capacity to delay reward in anorexia nervosa. J Int Neuropsychol Society. 2012;18(4):773-80 https://doi.org/10.1017/S1355617712000446.

111. Steinglass JE, Lempert KM, Choo T-H, Kimeldorf MB, Wall M, Walsh BT, Fyer AJ, Schneier FR, Simpson HB. Temporal discounting across three psychiatric disorders: anorexia nervosa, obsessive compulsive disorder, and social anxiety disorder. Depression Anxiety. 2017;34(5):463-70 https://doi.org/10. 1002/da.22586.

112. Stuhldreher N, Wild B, König H-H, Konnopka A, Zipfel S, Herzog W. Determinants of direct and indirect costs in anorexia nervosa. Int J Eat Disord. 2015;48(1):139-46 https://doi.org/10.1002/eat.22274

113. Thornton LM, Munn-Chernoff MA, Baker JH, Juréus A, Parker R, Henders AK, Larsen $\pi$, Petersen L, Watson HJ, Yilmaz Z, Kirk KM, Gordon S, Leppä VM, Martin FC, Whiteman DC, Olsen CM, Werge TM, Pedersen NL, Kaye W, et al. The anorexia nervosa genetics Initiative (ANGI): overview and methods. Contemporary Clinical Trials. 2018;74:61-9 https:/doi.org/10.1016/j.cct.2018.09.015.

114. Thornton LM, Trace SE, Brownley KA, Ålgars M, Mazzeo SE, Bergin JE, Maxwell M, Lichtenstein P, Pedersen NL, Bulik CM. A comparison of personality, life events, comorbidity, and health in monozygotic twins discordant for anorexia nervosa. Twin Research Human Genetics. 2017;20(4): 310-8 https://doi.org/10.1017/thg.2017.27.

115. Treasure J, Schmidt U. The cognitive-interpersonal maintenance model of anorexia nervosa revisited: A summary of the evidence for cognitive, socioemotional and interpersonal predisposing and perpetuating factors. J Eat Disord. 2013;1:13 https://doi.org/10.1186/2050-2974-1-13.

116. Treasure J, Zipfel S, Micali N, Wade T, Stice E, Claudino A, Schmidt U, Frank GK, Bulik CM, Wentz E. Anorexia nervosa. Nature Reviews Disease Primers. 2015;1:15074 https://doi.org/10.1038/nrdp.2015.74.

117. Tylee, D. S., Sun, J., Hess, J. L., Tahir, M. A., Sharma, E., Malik, R., Worrall, B. B., Levine, A. J., Martinson, J. J., Nejentsev, S., Speed, D., Fischer, A., Mick, E., Walker, B. R., Crawford, A., Grant, S. F. A., Polychronakos, C., Bradfield, J. P., Sleiman, P. M. A., ... Glatt, S. J. (2018). Genetic correlations among psychiatric and immune-related phenotypes based on genome-wide association data. Am Journal of Medical Genetics. Part B, Neuropsychiatric Genetics: The Official Publication of the International Society of Psychiatric Genetics, 177(7), 641-657. https://doi.org/10.1002/ajmg.b.32652.

118. Schwanenflug N. von, Müller DK, King JA, Ritschel F, Bernardoni F, Mohammadi S, Geisler D, Roessner V, Biemann R, Marxen M, Ehrlich S. Dynamic changes in white matter microstructure in anorexia nervosa: Findings from a longitudinal study. Psychol Med. 2019:49(9):1555-64.

119. Wade TD, Gillespie N, Martin NG. A comparison of early family life events amongst monozygotic twin women with lifetime anorexia nervosa, bulimia nervosa, or major depression. Int J Eat Disorders. 2007;40(8):679-86 https:// doi.org/10.1002/eat.20461.

120. Waterson MJ, Horvath TL. Neuronal regulation of energy homeostasis: beyond the hypothalamus and feeding. Cell Metab. 2015;22(6):962-70.

121. Watson, H. J., Yilmaz, Z., Thornton, L. M., Hübel, C., Coleman, J. R. I., Gaspar, H. A., Bryois, J., Hinney, A., Leppä, V. M., Mattheisen, M., Medland, S. E., Ripke, S., Yao, S., Giusti-Rodríguez, P., Anorexia Nervosa Genetics Initiative, Hanscombe, K. B., Purves, K. L., Eating Disorders Working Group of the Psychiatric Genomics Consortium, Adan, R. A. H., ... Bulik, C. M. (2019). Genome-wide association study identifies eight risk loci and implicates metabo-psychiatric origins for anorexia nervosa. Nat Genet, 51(8), $1207-$ 1214. https://doi.org/10.1038/s41588-019-0439-2.

122. Weinbach N, Perry A, Sher H, Lock JD, Henik A. Weak central coherence in weight-restored adolescent anorexia nervosa: Characteristics and remediation. Int J Eat Disord. 2017:50(8):924-32.

123. Westwood H, Stahl D, Mandy W, Tchanturia K. The set-shifting profiles of anorexia nervosa and autism spectrum disorder using the Wisconsin card sorting test: A systematic review and meta-analysis. Psychol Med. 2016;46(9): 1809-27 https://doi.org/10.1017/S0033291716000581.

124. Wierenga CE, Bischoff-Grethe A, Melrose AJ, Irvine Z, Torres L, Bailer UF, Simmons A, Fudge JL, McClure SM, Ely A, Kaye WH. Hunger does not motivate reward in women remitted from anorexia nervosa. Biol Psychiatry. 2015;77(7):642-52 https://doi.org/10.1016/j.biopsych.2014.09.024.

125. Wolff M, Krönke K-M, Venz J, Kräplin A, Bühringer G, Smolka MN, Goschke T. Action versus state orientation moderates the impact of executive functioning on real-life self-control. J Exp Psychol Gen. 2016;145(12):1635.

126. Wotton CJ, James A, Goldacre MJ. Coexistence of eating disorders and autoimmune diseases: record linkage cohort study, UK. Int J Eat Disord. 2016:49(7):663-72.
127. Yilmaz Z, Hardaway JA, Bulik CM. Genetics and epigenetics of eating disorders. Adv Genomics Genet. 2015;5:131.

128. Zerwas S, Larsen JT, Petersen L, Thornton LM, Quaranta M, Koch SV, Pisetsky D, Mortensen PB, Bulik CM. Eating disorders, autoimmune, and autoinflammatory disease. Pediatrics. 2017;140(6).

129. Zhu Y, Hu X, Wang J, Chen J, Guo Q, Li C, Enck P. Processing of food, body and emotional stimuli in anorexia nervosa: A systematic review and metaanalysis of functional magnetic resonance imaging studies. Eur Eating Disorders Review. 2012;20(6):439-50 https://doi.org/10.1002/erv.2197.

130. Zipfel S, Giel KE, Bulik CM, Hay P, Schmidt U. Anorexia nervosa: Aetiology, assessment, and treatment. Lancet Psychiatry. 2015;2(12):1099-111.

\section{Publisher's Note}

Springer Nature remains neutral with regard to jurisdictional claims in published maps and institutional affiliations.
Ready to submit your research? Choose BMC and benefit from:

- fast, convenient online submission

- thorough peer review by experienced researchers in your field

- rapid publication on acceptance

- support for research data, including large and complex data types

- gold Open Access which fosters wider collaboration and increased citations

- maximum visibility for your research: over $100 \mathrm{M}$ website views per year

At BMC, research is always in progress.

Learn more biomedcentral.com/submissions 